\title{
The Performance of the National Weather Service Heat Warning System against Ground Observations and Satellite Imagery
}

\author{
Jason Vargo, ${ }^{1,2}$ Qingyang Xiao, ${ }^{3}$ and Yang Liu ${ }^{3}$ \\ ${ }^{1}$ Nelson Institute Center for Sustainability and the Global Environment, University of Wisconsin-Madison, Madison, WI 53706, USA \\ ${ }^{2}$ Global Health Institute, University of Wisconsin-Madison, Madison, WI 53706, USA \\ ${ }^{3}$ Department of Environmental Health, Rollins School of Public Health, Emory University, Atlanta, GA 30322, USA
}

Correspondence should be addressed to Jason Vargo; javargo@wisc.edu

Received 31 March 2015; Accepted 26 May 2015

Academic Editor: Filomena Romano

Copyright (C) 2015 Jason Vargo et al. This is an open access article distributed under the Creative Commons Attribution License, which permits unrestricted use, distribution, and reproduction in any medium, provided the original work is properly cited.

\begin{abstract}
Deadly heat waves are increasing with climate change. Public forecasts and warnings are a primary public health strategy for dealing with such extreme weather events; however, temperatures can vary widely within the administrative units used to issue warnings, particularly across urban landscapes. The emergence of more frequent and widely distributed sources of urban temperature data provide the opportunity to investigate the specificity of the current National Weather Service (NWS) warnings and to improve their accuracy and precision. In this work, temperatures from distributed public weather stations, NWS heat advisories and warnings, and land surface temperature imagery throughout two large metropolitan areas, Atlanta and Chicago, during the 2006-2012 summers are considered. We investigate the spatial variability of hazardous temperatures and their agreement against NWS advisories. Second, we examine the potential for thermal imagery to replicate National Weather Service heat warnings. Observations from weather stations exhibit varying degrees of agreement with NWS advisories. The level of agreement varied by station and was not found to be associated with the station's proximate land cover. Air temperatures estimated from satellite imagery correspond with NWS Advisory status regionally and may enable creating more refined public warnings regarding hazardous temperatures and protective actions
\end{abstract}

\section{Introduction}

The potential for future extreme heat events that pose danger to human health is increasing with global climate change. As Hansen and colleagues at NASA's Goddard Institute for Space Studies put it, we have been loading the climate dice for the last 30 years, increasing the likelihood of meteorological events that used to occur once ever hundred years [1]. Models and recent historical records echo this sentiment with data and the recent news that atmospheric $\mathrm{CO}_{2}$ concentrations passed $400 \mathrm{ppm}$ for the first time in 3 million years imply that these trends are likely to continue. Early and accurate warnings are a crucial component for adapting to more frequent hazardous heat events.

The frequency, duration, areal coverage, and intensity of heat waves are expected to increase for most populated places because of global climate change $[2,3]$. Such events have caused major episodic mortality, including an estimated
70,000 excess deaths in Europe in 2003 [4] and more than 55,000 in Russia during July and August of 2010 [5, 6]. Heat wave characteristics like intensity and seasonality are also changing in ways that increase their potential hazard to health [7]. In many places, early warning systems are a key, if not the primary, component of measures for avoiding heat related deaths and illness. In the United States the National Weather Service (NWS) issues these warnings. In this work we are concerned with the spatial resolution and specificity of the issued warnings. The predictions for urban areas, in particular, could be improved given that cities are typically hotter than surrounding areas, concentrate people, and demonstrate great variability in temperatures and population vulnerabilities.

(a) Adaptation Strategies. The relationship between heat and health is well understood and known to change over time as well as with location and population characteristics [8]. 
Future changes in climate will increase adverse health impacts $[9,10]$. Adapting to changes in extreme heat events has largely followed three strategies: identifying vulnerable populations, ensuring access to mechanical cooling (air conditioning), and implementing early warning systems $[11,12]$.

Several studies using large population datasets and several summers of data demonstrate a positive relationship between temperatures and excess all-cause mortality on days that are abnormally warm compared to long-term summer weather for the region [13-15]. Public warning systems for heat are targeted toward managing such events. Response activities for heat events have been institutionalized as part of relatively recent efforts in some cities, including Chicago, Milwaukee, and Philadelphia following deadly heat waves in the early and mid 1990s [16, 17].

Deadly heat events have led to greater attention on individual and population level factors affecting heat vulnerability [18]. These include age, social isolation, housing type, income, and ethnicity $[19,20]$. Adaptive capacity of individuals is also a key determinant in whether and to what degree hazards of climate change will result in adverse health effects [21]. Understanding vulnerabilities to heat has led to efforts such as censuses of susceptible populations and doorto-door visits during heat events that have been shown to successfully reduce the related excess mortality [17, 22]. These approaches tend to be expensive to implement and rely on significant human resources for scaling up.

The most effective protection against hyperthermia in extreme weather is air conditioning (AC). The increased prevalence of this technology is one reason for declining heat-related mortality in the US despite increasing frequency of heat events [23]. However, reliance on energy-intensive adaptation strategies like AC results in greater energy use and the production of waste heat. Thus such adaptation measures produce positive feedbacks on global climate change and can exacerbate the urban heat island effect [24].

The general public are familiar with warning systems for weather-related hazards including floods, tornados, winds, and severe storms. As an adaptation strategy, warnings are important for quickly reaching large numbers of people at low cost and providing targeted messaging that can help minimize damages. Heat warning systems have been shown to save lives during extreme heat [16], but heat waves have received less attention than other natural disasters, in part, due to the fact that there is less aftermath (particularly property damage). Even when the public is aware of warnings and climatic conditions, there is often far less awareness of what protective actions should be taken [25].

(b) The National Weather Service Warnings. Currently the NWS uses four products based on the heat index (HI), a metric combining temperature and relative humidity to describe heat stress and discomfort, to issue hazard notifications. Heat index values are forecast for three to seven days out and are based on an ensemble of model and human forecasts. Day three forecasts are based on gridded model output statistics (MOS) temperature and dew point temperature forecasts. Forecasts on days four through seven rely on minimum and maximum 24-hour temperatures and dew points at 00 and 12
UTC supplied by the Weather Prediction Center's (WPC) 5$\mathrm{km}$ resolution grid data products. Probabilities for heat index values exceeding thresholds are also provided in the form of color filled displays. Probabilities are informed by uncertainty information from an ensemble of modeled forecasts and follow a normal distribution around mean MOS or WPC values assessed on a regular 20-km resolution grid [26].

The NWS produces criteria for extreme weather and potentially hazardous conditions.

Excessive Heat Outlook may be issued 3 to 7 days prior to a heat episode requiring issuance of a heat warning, provided forecaster confidence is relatively high.

Excessive Heat Watch may be issued 12 to 48 hours prior to heat episode with a 50 percent chance or greater of daytime heat indices equal to or greater than $110^{\circ} \mathrm{F}$ for at least two consecutive days.

Heat Advisory is issued in the first and/or second period when there is an 80 percent chance or greater of daytime heat indices equal to or greater than $105^{\circ} \mathrm{F}\left(40.6^{\circ} \mathrm{C}\right)$ for at least two consecutive days.

Excessive Heat Warning is issued in the first and/or second period when there is an 80 percent or greater of daytime heat indices equal to or greater than $110^{\circ} \mathrm{F}\left(43.3^{\circ} \mathrm{C}\right)$ for at least two consecutive days.

These criteria can be modified for specific regions and cities as the local offices see fit. For example, the city of Chicago uses additional criteria related to nighttime low temperatures to trigger advisories.

The NWS's advisory guidelines are, by default, applied uniformly for different places across the country. In this respect they have not been representative of regional adaptation behaviors and practices. This leads to warnings and advisories in some areas that may be issued too frequently or not frequently enough and that misrepresent actual weatherrelated risks for people. In both cases the issuances may lead to skepticism and neglect for the NWS notifications and decrease their effectiveness. In recent years some areas, like the city of Chicago, have been more proactive about defining their own criteria not only for daytime high as well as nighttime low HI. Other cities, like Philadelphia, PA, has employed their own heat watch and warning systems [27].

Other concerns with the NWS advisories and warnings relate to urban areas where anthropogenic land cover modifications may elevate temperatures dangerously high even outside periods of regional extreme weather. Hazardous thermal conditions may also exist in small pockets of the urban landscape, which displays great variability in temperatures over space. The current NWS notification system is based on low resolution forecast model grids, relative to heterogeneity in urban landscapes and surface temperatures, and releases warnings and advisories at the county level. Because counties vary in size from place to place and may not completely contain major population centers, the NWS products could fail to provide specific warnings and meaningful guidance for large numbers of people. Even if the products are accurately predicting regional hot weather, detail to the spatial distribution of temperatures within the region could improve warnings, individual adaptation measures, and larger response efforts. 
Previous work has examined whether the HI values used are indicative of health threats by comparing HI values and mortality for various locations [28]. Like the NWS products the HI values are often collected at a single site and used to represent an entire region. Regionally representative combinations of temperature and humidity have also been compared with mortality and morbidity rates in places [29]. The outcome of such studies has shown that HI can be a useful metric for informing decisions to protect public health in some locations. Alternatives based on weather classifications, like the Synoptic Spatial Classification (SSC), have also been examined for agreement with variability in mortality. The NWS system was compared against public perceptions of heat risk, a determining factor in whether precautionary actions are taken, and found to vary between regions and across age, income, gender, and ethnicities within regions [30].

(c) New Data Sources. In situ and remote sensors of temperature at or near the Earth's surface offer the potential to improve the current warning system by increasing its specificity, particularly with regard to location. These data sources are new and numerous. They provide data with greater spatial coverage, frequent revisit times, and low cost. Distributed weather stations may have a shorter history than reliable long term stations used in climatological studies but can effectively describe spatial patterns in temperatures across the urban landscape. Satellite data products like land surface temperature (LST) from the Moderate Resolution Imaging Spectroradiometer (MODIS) sensors offer $1 \mathrm{~km}$ spatial resolution data for areas around the globe up to four times daily [31]. Such products are systematically processed to remove inconsistencies and distortions, as well as to calculate usable temperature outputs. While these data cannot currently offer predictive weather information, they are nonetheless useful for analyzing and describing spatial variation and patterns which, when combined with predictive models currently in use, can improve information to the public and the adaptive response.

(d) Investigations. In this work we consider temperatures from distributed public weather stations, NWS heat advisories and warnings, and land surface temperature imagery throughout two large metropolitan areas, Atlanta and Chicago, during the summers from 2006 to 2012 . We first investigate the spatial variability in hazardous temperatures and agreement with advisories issued by the NWS, and second we examine the potential for a widely available thermal imagery product to replicate National Weather Service heat warnings.

Here we test two primary hypotheses. The first is that measured data from local stations will exhibit the conditions for heat warnings at the same time and place as NWS forecasted warnings. We expect to find that the NWS advisories miss some instances where hazardous heat conditions are met at locations within counties. We will examine some of the characteristics of such locations, should they exist.

Second, we examine specific days where there is some evidence of extreme heat in either the NWS or surface station records. These days help describe whether estimates of near surface air temperatures at subcounty resolutions can improve the identification of hazardous thermal conditions. We investigate estimates derived from LST collected by satellites coupled with station measurements. We expect to find that LST and station records are well correlated, particularly on NWS-determined advisory days. This would suggest that satellite data may provide a means of identifying hazardous heat conditions where stations do not exist and at scales finer that forecast models. The findings from these tests are expected to improve the existing national heat warning system by demonstrating the need for subcounty specification that the current system misses and by providing evidence for how existing data sources could be used to complement the current NWS system.

\section{Methods}

2.1. Study Locations. This study focuses on two metropolitan areas in different climatic zones of the US: Atlanta, GA, and Chicago, IL (see Figure 1). Atlanta is an inland city in the southeastern US (centered near 84.37 W, 33.74 N). Atlanta's historic downtown and central city are located primarily in Fulton County. A portion of the city sits in DeKalb County east of Fulton. Three other counties (two north and one south of the city) were included in the analysis to cover the core of the metropolitan area: Clayton, Cobb, and Gwinnett. Chicago is in the midwest and sits on the large water body of Lake Michigan (centered near $87.63 \mathrm{~W}, 41.89 \mathrm{~N}$ ). The city of Chicago sits within Cook County. Four surrounding counties (DuPage to the west, Lake, IL to the north, Will to the southwest, and Lake, IN to the southeast) were also included in the analysis of the Chicago Metro area.

2.2. Heat Advisory Data. As for the historical record of heat warnings, we used NWS-issued Heat Advisories and Excessive Heat Warnings. Text records of the statements issued by NWS stations are archived and maintained by the National Oceanic and Atmospheric Administration's (NOAA) National Climatic Data Center (NCDC). The data are stored in the Hierarchical Data Storage System (HDSS), which includes a tape robotics system for data archived on tape. NCDC provides direct online access to these data through the HDSS Access System (HAS). Weather statements were issued from two NWS stations responsible for the Atlanta (KFFC, Peachtree City, Falcon, GA) and Chicago (KLOT, Lewis University, IL) Metropolitan Areas. Specifically, recorded Heat Advisories and Excessive Heat Warnings are contained in Non-Precipitation Watches, Warnings, Advisories Bulletins (bulletin ID WWUS7) and are accessible through the Service Records Retention System (SRRS) Text Products/Bulletin Selection interface (available at http://has .ncdc.noaa.gov/pls/plhas/HAS.StationYearSelect). Text file compilations of bulletins were obtained for May 1 to September 30 for the years 2006-2012. Individual text files were combed to identify mention of "HEAT" and were further examined to determine the day-county to which Heat Advisories or Excessive Heat Warnings applied. 


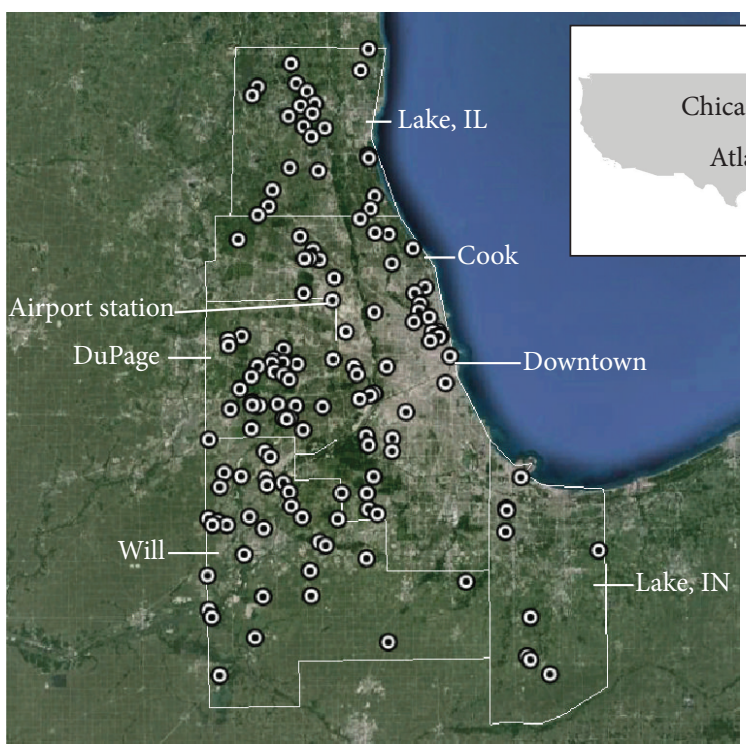

Images: Google Earth-digital globe (b)

FIgURE 1: The five-county study areas of Chicago (a) and Atlanta (b) are shown. Weather stations (including the airport stations) are shown with dotted circles.

\subsection{Weather Station Data. Measurements from weather sta-} tions serve as diagnostics of whether or not a hazardous heat event actually occurred for a given location and day. Two data sources were used for weather station data. First, temperature and humidity data from NCDC's Surface Data, Hourly Global (DS3505) data were obtained for Atlanta Hartsfield International Airport (USW00013874) and Chicago O'hare International Airport (USW00094846) from the NCDC website (http://www.ncdc.noaa.gov/cdo-web/datasets/). Second, Weather Underground, a commercial weather service provider, established a personal weather station network, which they use to inform their BestForecast system. The Weather Underground network allows individuals to share real-time weather information recorded by personal weather stations. The measurement intervals range between 1 and 60 minutes and differ by station. Temperature $\left({ }^{\circ} \mathrm{F}\right)$ and relative humidity (\%) from 64 stations in five counties in the Atlanta metro area and 144 stations in five counties in the Chicago metro area (see Figure 1) were obtained from the Weather Underground website (http://www.wunderground.com/ accessed in Sep-Oct 2013). Stations within the ten counties were queried for hourly temperature and humidity data back to May 2006. Since the Weather Underground network is continuously expanding, stations used in the analysis may differ from those assembled when this paper is being read.

To control the quality of data and eliminate outliers, for each city, we removed observations beyond the range of mean \pm five standard deviations. For each station, days with less than 16 hours valid hourly data and years with less than $75 \%$ valid daily data were also excluded to eliminate possible sampling bias. The hourly average temperature and relative humidity values were processed to calculate the HI based on algorithms provided by the NWS (http://www.hpc.ncep.noaa .gov/html/heatindex_equation.shtml). To evaluate if stations experienced hazardous heat conditions, the NWS definition of Heat Advisory was used, such that if there are at least two consecutive days with at least one hourly HI greater than $105^{\circ} \mathrm{F}\left(40.6^{\circ} \mathrm{C}\right)$ in each day, these days were marked as heat wave days.

2.4. Land Surface Temperature Imagery. The potential for regularly collected satellite data to provide more information on within-county variability in hazardous temperatures is examined through images from May through September 2011-2012 in the Atlanta and Chicago Metropolitan cores.

The daily $1 \mathrm{~km}$ land surface temperature (LST) data [32] from MODIS aboard the National Aeronautics and Space Administration (NASA) Earth Observing System (EOS) Aqua and Terra satellite, labeled as MYD11_A1 and MOD11_A1, were obtained from the Goddard Space Flight Center (http://ladsweb.nascom.nasa.gov). We extracted the LST parameter "LST_Day_1 km" and "LST_Night_1 km" at 1 $\times 1 \mathrm{~km}$ spatial resolution over Atlanta and Chicago. Retrievals with quality flags of "fair consistency" and "good consistency" were included in the following analyses. The $1 \mathrm{~km}$ monthly MODIS normalized difference vegetation index (NDVI) product (MOD13 A3) was obtained from the Goddard Space Flight Center (http://ladsweb.nascom.nasa.gov).

To integrate the air temperature measurements, spatial predictors, and LST retrievals, we projected all the data to the MODIS Sinusoidal Grid. Each Weather Underground station was assigned to the LST pixels of the same grid cell. The NDVI 


\begin{tabular}{|c|c|c|c|c|c|c|c|c|}
\hline Metro & County & 2006 & 2007 & 2008 & 2009 & 2010 & 2011 & 2012 \\
\hline Atlanta & Clayton & & 116 & & & \begin{tabular}{|l|l|}
$\| \mid$ & 9
\end{tabular} & | | 4 & I \\
\hline & Cobb & & II 5 & & & III 7 & | | 4 & i \\
\hline & Dekalb & & II 5 & & & III 7 & | | 4 & I \\
\hline & Fulton & & II 5 & & & III 7 & | | 4 & I \\
\hline & Gwinnett & & II 5 & & & III 7 & 11 & I \\
\hline Chicago & Cook & & & & & | 14 & | ||| & \|\| \\
\hline & DuPage & & & & $1 \quad 3$ & | I 4 & | II|| & III \\
\hline & Lake, IL & & & & $1 \quad 2$ & I 3 & III & ||| \\
\hline & Lake, IN & & & & \begin{tabular}{l|l}
1 & 2
\end{tabular} & | I 4 & $\mid$ & ||| \\
\hline & Will & & & & 113 & I I 4 & $\mid \|$ & \|\| \\
\hline
\end{tabular}

Figure 2: Recorded National Weather Service Heat Advisories are shown (black) for May-September 2006-2012 by county. Annual county totals are also shown.

value, average elevation value, and percent impervious area value were constructed based on the same grid.

Following a published methodology [33] we developed a linear mixed effect model to estimate the daily average air temperature from LST retrievals. The model consisted of dayspecific random intercepts and random LST slopes as follows:

$$
\begin{aligned}
& \mathrm{AT}_{i j}= \beta_{0}+u_{j}+\left(\beta_{1}+v_{j}\right) \mathrm{LST}_{i j}+\beta_{2} \text { elev }_{i} \\
&+\beta_{3} \text { impervPCT }_{i}+\beta_{4} \mathrm{NDVI}_{i j}+e_{i j} \\
& \sim\left(0, \sigma^{2}\right), \\
&\left(u_{j}, v_{j}\right) \sim(\mathbf{0}, \boldsymbol{\Sigma}),
\end{aligned}
$$

where $\mathrm{AT}_{i j}\left({ }^{\circ} \mathrm{F}\right)$ is the measured air temperature in grid cell $i$ on day $j ; \beta_{0}$ denotes the fixed intercept; $u_{j}$ denotes the day-specific random intercept; $\beta_{1-4}$ are the fixed slopes of LST, elev, impervPCT, and NDVI, respectively; $v_{j}$ is the day-specific random slope of LST; LST $_{i j}$ is the land surface temperature retrieval in grid cell $i$ on day $j$; impervPCT $\mathrm{P}_{i}$ is the percent of impervious area in grid cell $i$; $\mathrm{NDVI}_{i j}$ is the monthly NDVI value in grid cell $i$ for the month in which day $j$ falls; $\operatorname{elev}_{i}$ (meters) is the mean elevation in grid cell $i$; $e_{i j}$ is the error term in grid cell $i$ on day $j$.

We also considered wind speed as a predictor in the model; however, preliminary results indicated that it was not significant and it was removed from the model. We used both daytime and nighttime LST retrievals from both Terra and Aqua satellite as the predictors and evaluated the model performance, respectively. The average night LST was selected as the predictor in the final model because it provides the highest accuracy and greatest coverage. The average nighttime LST is defined as the night LST from Aqua or the night LST from Terra if only one of them is available; if both Aqua and Terra night LSTs are available, the average night LST is the mean of these two values. Fivefold cross validation (CV) was used to validate our model performance. We randomly divided the data into a training dataset $(80 \%)$ and a testing dataset $(20 \%)$ and then made predictions for testing dataset using the model fitted from the training dataset. The model was trained and tested for five times by different training and testing datasets to ensure that each data point ends up in the testing dataset exactly once. This process was repeated for 1,000 times and the root meansquare prediction errors (RMSPE) and $R^{2}$ were reported to estimate the model prediction precision. The RMSPE were calculated as follows:

$$
\text { RMSPE }=\sqrt{\sum_{i=1}^{N} \frac{\left(P_{i}-O_{i}\right)^{2}}{N}},
$$

where $N$ is the number of observations and $P_{i}$ and $O_{i}$ are the $i$ th predicted and observed value, respectively.

\section{Results}

3.1. Data Descriptions. Among records from the airport and Weather Underground weather stations from MaySeptember 2006-2012 there are 26,943 and 70,312 valid station-day data records in total for Atlanta and Chicago, respectively, and 1,172 and 1,499 station days were marked as heat wave days. This is $4.3 \%$ of daily observations meeting Heat Advisory conditions in Atlanta and 2.14\% in Chicago. In the years 2011 and 2012 there was far less missing data among stations. In these years there were 14,086 and 34,347 observations with 694 (4.9\%) and 1,143 (3.3\%) station days exceeded Heat Advisory criteria.

Both 2011 and 2012 featured several NWS Heat Advisories in the two metro regions. Several years prior featured no NWS-issued Heat Advisories for the core metro counties. In Atlanta 2006, 2008, and 2009 had no Advisories, and in the Chicago counties 2006-2008 were without Heat Advisories (see Figure 2). In Atlanta, Heat Advisories were mostly applied to the five counties in the core metro area uniformly. That is, on days for which an advisory was issued it was applied to all counties. In only three instances Clayton county was issued a warning when other counties were not. In 2011 there were two Heat advisories in each month of July and August, and in 2012 there were four concurrent advisories that spanned June and July. In Chicago there was more variability in issuing NWS Advisories, particularly in July of 2011. In that month both Cook and DuPage Counties were issued six Advisories, Lake, Illinois had four, and both Lake, Indiana and Will County experienced eight. All five Chicago area counties experienced the same number of advisories in other months: one in August 2011, two in June 2012, and seven in July 2012.

The majority of the Wunderground Stations are found on "developed" land cover of some type. Of Atlanta's 57 stations, most were located on high-, medium-, and low-intensity and 
open space developed land. Only 9 stations were located on land covers not considered developed (four evergreen forests, four deciduous forests, and one woody wetland). In Chicago 10 of the 137 (7.3\%) stations were found on land covers other than some form of "developed." All of Cook county's 44 stations are found on low-, medium-, or high intensity developed land (see Tables 1 and 2).

3.2. Comparing NWS and Station Data. To test the agreement of hazardous heat conditions at stations with the NWS Advisories, we treated the station measurements as the diagnostic gold standard against which the NWS notifications were compared. A false negative test, thus, describes an instance in which the daily heat index measured at the station met the criteria for a Heat Advisory without an official NWSissued Advisory. In both metro areas the average number of false negatives and false positives differed significantly from perfect agreement (see Tables 1 and 2). This was true for both 2011 and 2012 and across different land covers for which there were more than 10 examples.

The average number of false positives per station per year in Chicago (4.80) was much higher than the average number of false negatives (1.96), which was slightly less than the number of true positive days where stations and NWS notifications agreed (2.92), while in Atlanta, the average number of false positives (1.98) was much lower than the number of false negatives per station (5.28), both of which were greater than the days/year of station-NWS agreement (1.87). The results suggest that the NWS-issued Heat Advisories in Chicago covered many instances when hazardous conditions were never reached at stations, and in Atlanta the Advisories were more likely to miss instances of hazardous conditions at specific locations. Some stations in each metro area exhibited a high degree of disagreement between stations and the NWS (see Figure 3); however, no pattern related to land cover or location emerged to explain these variations.

3.3. Comparing Satellite Imagery and Temperatures. Three specific categories of summer days were investigated more closely in each metro area using satellite data on LST. These categories were identified using the NWS Heat Advisory status and general trends among the metro's weather stations. In Atlanta, for example, on July 1, 2012 NWS issued a Heat Advisory for all five counties in the metro area and nearly all of the stations (87.7\%) met the conditions for the Advisory. An NWS Advisory was also issued on June 29, 2012; however only about half (47.4\%) of stations met Advisory conditions. In the third case, on July 25, 2012 just under half (48.3\%) of the stations exhibited Advisory conditions but no NWS Heat Advisory was issued. In Chicago July 6, 2012 was a NWS Heat Advisory with agreement from $93.8 \%$ of stations. July 17 , 2012 was another NWS Heat Advisory, but with only $42.1 \%$ of stations in agreement. Finally, July 2, 2012 was an example of several stations (49.6\%) exhibiting Advisory conditions without a NWS-issued Advisory.

We examined these six days in detail using MODIS imagery to produce estimated daily mean air temperatures. Our mixed effects model with the average night LST as the predictor and average daily air temperature as the dependent variable fits the dataset well and provides high prediction precision. For the model fittings, the $R^{2}$ is 0.71 and 0.74 in Chicago and Atlanta, respectively. For the fivefold CV, the $R^{2}$ and RMSPE are 0.697 and $1.92^{\circ} \mathrm{F}$ in Chicago, respectively; and $R^{2}$ and RMSPE are 0.711 and $1.75^{\circ} \mathrm{F}$ in Atlanta, respectively. We used this model to predict the mean daily temperature over Chicago and Atlanta on three typical days, respectively.

In both metro areas, the days on which there was high agreement between stations and NWS had higher estimated air temperatures (see Figures 4(a) and 4(b)). Even when there was daily disagreement among stations ((c)-(f)), the estimated temperatures on NWS Heat Advisory days ((c) and (d)) are higher than on days when there was no Advisory ((e) and (f)). The results support the merits of each dataset: the NWS Advisories appear to correspond to higher regional temperatures as estimated from LST, and station data help to identify specific locations of hazardous heat, particularly on days when no NWS Heat Advisory is issued.

\section{Discussion}

This work describes some fundamental characteristics of the NWS warning system for heat. The NWS system does well capturing regional weather movements which result in hazardously warm weather, and it delivers early information to large populations. This work highlights how the NWS lacks the spatial precision to inform more carefully targeted interventions which could save lives during regional heat events. The broad applicability of the NWS Heat Advisories and Warnings leads them to warn of the existence of hazardous heat conditions for places on summer days when such conditions are not present and to miss several instances of hazardous conditions in metro areas on days for which regional weather patterns may not trigger a warning. This work used relatively new and quickly growing datasets like unregulated and noncentralized weather stations as well as daily satellite imagery to demonstrate how the coverage and resolution of heat conditions within metro areas may be better represented and studied.

Moving forward, increased attention should be devoted to uncovering the drivers of non-NWS Advisory hot spots with urban areas. The existence and mechanisms of the urban heat island are well understood but largely considered only by research and science communities, rather than local planning entities [34]. The existence of datasets, like those used in this study, present the opportunity for cities to understand and identify where and how local topography, climate, and demographics interact to create elevated climate-related health risks. One example of such practice already being adopted is with Chicago's Sustainability Office and their use of Landsat imagery to identify hotspots, which then serve as an inventory of priority locations for new green infrastructure investments (http://news.satimagingcorp.com/2006/10/chicago_uses_satellite_images_to_determine_citys_true_hot_spots .html) [35].

The opportunities to improve the existing NWS early warning system are considerable, particularly given the 
TABLE 1: Atlanta weather station details on the number of normal ("Norm") and Advisory ("Heat") days during the summer of 2011 and 2012. The total number of false positives (no station hazard with NWS advisory) and false negatives (station hazard with no NWS Advisory) is also provided to give an idea of the agreement between the station and the NWS Advisories for that county.

\begin{tabular}{|c|c|c|c|c|c|c|c|c|c|c|}
\hline \multirow{2}{*}{$\begin{array}{l}\text { Metro } \\
\text { County } \\
\text { Station }\end{array}$} & \multirow{2}{*}{ Land cover (NLCD 2011) } & \multicolumn{3}{|c|}{2011} & \multicolumn{3}{|c|}{2012} & \multirow{2}{*}{ False pos. } & \multirow{2}{*}{ False neg. ${ }^{*}$} & \multirow{2}{*}{ Obs } \\
\hline & & Norm & Heat & $\%$ & Norm & Heat & $\%$ & & & \\
\hline \multicolumn{11}{|l|}{ Atlanta } \\
\hline \multicolumn{11}{|l|}{ Clayton } \\
\hline KGAATLAN58 & Developed high intensity & & & & 146 & 6 & $4 \%$ & 2 & 4 & 152 \\
\hline ATLAirport & Developed low intensity & 153 & 0 & $0 \%$ & 151 & 2 & $1 \%$ & 6 & 0 & 306 \\
\hline \multicolumn{11}{|l|}{ Cobb } \\
\hline KGAMARIE40 & Deciduous forest & 120 & 26 & $18 \%$ & 126 & 14 & $10 \%$ & 2 & 34 & 286 \\
\hline KGAACWOR9 & Developed open space & 151 & 2 & $1 \%$ & 134 & 18 & $12 \%$ & 3 & 15 & 305 \\
\hline KGAPOWDE3 & Developed open space & 142 & 11 & $7 \%$ & 148 & 5 & $3 \%$ & 2 & 10 & 306 \\
\hline KGAMABLE1 & Evergreen forest & 145 & 8 & $5 \%$ & 149 & 4 & $3 \%$ & 3 & 7 & 306 \\
\hline MD0601 & Developed open space & 144 & 7 & $5 \%$ & 146 & 5 & $3 \%$ & 2 & 6 & 302 \\
\hline KGAMARIE25 & Developed open space & & & & 124 & 7 & $5 \%$ & 1 & 4 & 131 \\
\hline KGAMABLE3 & Developed open space & 142 & 7 & $5 \%$ & 144 & 3 & $2 \%$ & 2 & 4 & 296 \\
\hline KGAMARIE43 & Developed low intensity & 113 & 5 & $4 \%$ & 150 & 3 & $2 \%$ & 2 & 2 & 271 \\
\hline KGAMARIE42 & Developed open space & 148 & 3 & $2 \%$ & & & & 2 & 1 & 151 \\
\hline KGAMARIE34 & Developed low intensity & 121 & 0 & $0 \%$ & & & & 2 & 0 & 121 \\
\hline KGAMARIE35 & Developed open space & 148 & 0 & $0 \%$ & 134 & 3 & $2 \%$ & 5 & 0 & 285 \\
\hline KGAMARIE20 & Developed low intensity & 153 & 0 & $0 \%$ & 150 & 3 & $2 \%$ & 5 & 0 & 306 \\
\hline KGAROSWE4 & Developed open space & 152 & 0 & $0 \%$ & 120 & 2 & $2 \%$ & 6 & 0 & 274 \\
\hline KTGAMARI2 & Deciduous forest & & & & 132 & 2 & $1 \%$ & 2 & 0 & 134 \\
\hline KGAMARIE46 & Developed medium intensity & & & & 134 & 2 & $1 \%$ & 2 & 0 & 136 \\
\hline KGAKENNE16 & Developed open space & & & & 148 & 2 & $1 \%$ & 2 & 0 & 150 \\
\hline KGAKENNE15 & Developed low intensity & 120 & 2 & $2 \%$ & 149 & 2 & $1 \%$ & 4 & 0 & 273 \\
\hline KGAMARIE39 & Woody wetlands & 148 & 2 & $1 \%$ & 150 & 2 & $1 \%$ & 4 & 0 & 302 \\
\hline KGASMYRN2 & Developed low intensity & 128 & 0 & $0 \%$ & 145 & 0 & $0 \%$ & 6 & 0 & 273 \\
\hline MAT950 & Developed open space & 147 & 0 & $0 \%$ & 132 & 0 & $0 \%$ & 7 & 0 & 279 \\
\hline \multicolumn{11}{|l|}{ Dekalb } \\
\hline KGADECAT8 & Developed open space & 128 & 25 & $16 \%$ & 136 & 17 & $11 \%$ & 2 & 36 & 306 \\
\hline KGAAVOND3 & Developed high intensity & & & & 128 & 24 & $16 \%$ & 2 & 22 & 152 \\
\hline KGAAVOND4 & Developed low intensity & & & & 147 & 2 & $1 \%$ & 2 & 0 & 149 \\
\hline KGAATLAN52 & Evergreen forest & 149 & 0 & $0 \%$ & 148 & 0 & $0 \%$ & 8 & 0 & 297 \\
\hline \multicolumn{11}{|l|}{ Fulton } \\
\hline KGAATLAN41 & Developed low intensity & 96 & 53 & $36 \%$ & 114 & 24 & $17 \%$ & 2 & 71 & 287 \\
\hline KGAATLAN70 & Developed open space & & & & 77 & 39 & $34 \%$ & 0 & 35 & 116 \\
\hline KGAALPHA10 & Developed low intensity & 128 & 22 & $15 \%$ & 135 & 18 & $12 \%$ & 1 & 33 & 303 \\
\hline KGAATLAN67 & Deciduous forest & & & & 127 & 26 & $17 \%$ & 1 & 23 & 153 \\
\hline KGAROSWE5 & Developed low intensity & 117 & 9 & $7 \%$ & 131 & 13 & $9 \%$ & 1 & 17 & 270 \\
\hline MD5335 & Developed open space & & & & 137 & 16 & $10 \%$ & 4 & 16 & 153 \\
\hline KGAATLAN56 & Developed open space & 125 & 13 & $9 \%$ & & & & 2 & 12 & 138 \\
\hline KGAJOHNS2 & Developed low intensity & 143 & 10 & $7 \%$ & 147 & 5 & $3 \%$ & 4 & 12 & 305 \\
\hline KGAATLAN54 & Developed medium intensity & 139 & 11 & $7 \%$ & 129 & 2 & $2 \%$ & 4 & 9 & 281 \\
\hline KGAJOHNS5 & Developed open space & 151 & 2 & $1 \%$ & 148 & 5 & $3 \%$ & 3 & 2 & 306 \\
\hline KGAATLAN16 & Developed low intensity & 148 & 4 & $3 \%$ & 148 & 3 & $2 \%$ & 3 & 2 & 303 \\
\hline
\end{tabular}


TABle 1: Continued.

\begin{tabular}{|c|c|c|c|c|c|c|c|c|c|c|}
\hline \multirow{2}{*}{$\begin{array}{l}\text { Metro } \\
\text { County } \\
\text { Station }\end{array}$} & \multirow{2}{*}{ Land cover (NLCD 2011) } & \multicolumn{3}{|c|}{2011} & \multicolumn{3}{|c|}{2012} & \multirow{2}{*}{ False pos. } & \multirow{2}{*}{ False neg. ${ }^{*}$} & \multirow{2}{*}{ Obs } \\
\hline & & Norm & Heat & $\%$ & Norm & Heat & $\%$ & & & \\
\hline KGAATLAN37 & Developed low intensity & 145 & 4 & $3 \%$ & 149 & 2 & $1 \%$ & 4 & 2 & 300 \\
\hline MAT910 & Developed medium intensity & 141 & 3 & $2 \%$ & 143 & 3 & $2 \%$ & 3 & 1 & 290 \\
\hline KGAATLAN40 & Developed low intensity & 147 & 4 & $3 \%$ & 149 & 2 & $1 \%$ & 3 & 1 & 302 \\
\hline KGAATLAN57 & Developed open space & 149 & 3 & $2 \%$ & 150 & 2 & $1 \%$ & 4 & 1 & 304 \\
\hline KGAALPHA16 & Developed open space & 119 & 0 & $0 \%$ & & & & 0 & 0 & 119 \\
\hline KGAPALME2 & Deciduous forest & & & & 125 & 2 & $2 \%$ & 2 & 0 & 127 \\
\hline KGAATLAN50 & Developed open space & 148 & 2 & $1 \%$ & 138 & 2 & $1 \%$ & 4 & 0 & 290 \\
\hline KGAATLAN49 & Developed medium intensity & 141 & 0 & $0 \%$ & 149 & 0 & $0 \%$ & 8 & 0 & 290 \\
\hline KGAMOUNT2 & Developed open space & 147 & 0 & $0 \%$ & 153 & 0 & $0 \%$ & 8 & 0 & 300 \\
\hline \multicolumn{11}{|l|}{ Gwinnett } \\
\hline KGALILBU10 & Evergreen forest & 120 & 28 & $19 \%$ & 112 & 36 & $24 \%$ & 1 & 57 & 296 \\
\hline KGADULUT7 & Developed open space & & & & 114 & 34 & $23 \%$ & 0 & 30 & 148 \\
\hline KGALAWRE13 & Developed open space & 131 & 22 & $14 \%$ & 140 & 5 & $3 \%$ & 5 & 24 & 298 \\
\hline KGALOGAN12 & Evergreen forest & 138 & 13 & $9 \%$ & 127 & 5 & $4 \%$ & 2 & 13 & 283 \\
\hline KGASTONE4 & Developed low intensity & & & & 147 & 6 & $4 \%$ & 1 & 3 & 153 \\
\hline KGALILBU11 & Developed low intensity & 122 & 4 & $3 \%$ & 112 & 3 & $3 \%$ & 3 & 2 & 241 \\
\hline KGALILBU4 & Developed low intensity & 153 & 0 & $0 \%$ & 151 & 2 & $1 \%$ & 6 & 0 & 306 \\
\hline KGALILBU8 & Developed open space & 151 & 2 & $1 \%$ & 151 & 2 & $1 \%$ & 4 & 0 & 306 \\
\hline KGALAWRE6 & Developed open space & 151 & 0 & $0 \%$ & 152 & 0 & $0 \%$ & 8 & 0 & 303 \\
\hline KGANORCR12 & Developed low intensity & 144 & 2 & $1 \%$ & 151 & 0 & $0 \%$ & 6 & 0 & 297 \\
\hline KGANORCR14 & Developed open space & 148 & 0 & $0 \%$ & 121 & 0 & $0 \%$ & 8 & 0 & 269 \\
\hline
\end{tabular}

${ }^{*}$ Stations within each county are sorted by number of false negatives.

growing number of networked weather stations within urban areas. The Wunderground network of stations is but one of several sites aggregating information from such distributed environmental monitoring systems. Weather Bug is another network which was used in the original study using MODIS data to generate a surface of estimated air temperatures [33]. The ability of imagery to provide increased coverage and resolution for urban temperatures continues to be explored and improved [36]. New processing techniques, such as those used here, which combine remotely sensed thermal data with in situ temperature readings offer the potential for cities to obtain recurring descriptions of intraurban temperature variation. Patterns that emerge from examining the urban thermal environmental over years could help improve public expenditures for reducing the urban heat island, for example, by increasing green space. These investments can be important parts of municipal strategies to combat climate change and improve quality of life through the multiple cobenefits that such strategies offer [37].

Warning systems for natural hazards have improved most for non-heat-related threats [38]. For example, in 2007 the NWS has developed storm-based warnings for tornados as an alternative to countywide warnings. New data sources can improve precision of heat modeling and forecasting in metropolitan areas and may help with the reception of warning messages. This is particularly true as more of the public obtain weather information through interactive displays and interfaces. Compared with message delivery via radio, or static maps, meteorological information is increasingly made available on location-smart devices and with animated visualizations of weather conditions describing recent historic and near future weather conditions with improved precision $[39,40]$. As users become used to this form of weather information, more specific forecasts of local heat can improve individual response and public trust of warnings [41]. The location- and time-specific information available from such networks can also be paired with mobile technology to provide targeted warnings to subscribers within a certain distance of stations when they are exhibiting hazardous conditions. Mobile weather applications are already beginning to use location-aware devices' abilities to improve information delivery and some, such as Weather Underground's mobile app, allow users to provide "Hazard Reports" for their current location to crowdsource information on conditions such as power outages, road closures, and flooding.

In our analysis we found the estimated air temperatures produced from combining LST with station observations to capture the general patterns also described by the NWS warning classification, we do not find it to capture all of the heterogeneity in the weather station data. This may be due to the inability of LST-produced estimates to reflect the importance of humidity in determining human health 
TABLE 2: Chicago weather station details on the number of normal ("Norm") and Advisory ("Heat") days during the summer of 2011 and 2012. The total number of false positives (no station hazard with NWS Advisory) and false negatives (station hazard with no NWS Advisory) is also provided to give an idea of the agreement between the station and the NWS Advisories for that county.

\begin{tabular}{|c|c|c|c|c|c|c|c|c|c|c|}
\hline \multirow{2}{*}{$\begin{array}{l}\text { Metro } \\
\text { County } \\
\text { Station }\end{array}$} & \multirow{2}{*}{ Land cover (NLCD 2011) } & \multicolumn{3}{|c|}{2011} & \multicolumn{3}{|c|}{2012} & \multirow{2}{*}{ False pos. ${ }^{*}$} & \multirow{2}{*}{ False neg. } & \multirow{2}{*}{ Obs } \\
\hline & & Norm & Heat & $\%$ & Norm & Heat & $\%$ & & & \\
\hline \multicolumn{11}{|l|}{ Chicago } \\
\hline \multicolumn{11}{|l|}{ Cook } \\
\hline KILWESTC4 & Developed low intensity & 152 & 0 & $0 \%$ & 149 & 0 & $0 \%$ & 16 & 0 & 301 \\
\hline KILCHICA106 & Developed high intensity & 153 & 0 & $0 \%$ & 151 & 2 & $1 \%$ & 14 & 0 & 306 \\
\hline KILCHICA86 & Developed high intensity & 149 & 2 & $1 \%$ & 153 & 0 & $0 \%$ & 14 & 0 & 304 \\
\hline KILCHICA52 & Developed high intensity & 151 & 0 & $0 \%$ & 150 & 3 & $2 \%$ & 13 & 0 & 304 \\
\hline KILLINCO6 & Developed medium intensity & 135 & 2 & $1 \%$ & 153 & 0 & $0 \%$ & 13 & 0 & 290 \\
\hline KILCHICA37 & Developed high intensity & 151 & 2 & $1 \%$ & 151 & 2 & $1 \%$ & 12 & 0 & 306 \\
\hline KILORLAN3 & Developed low intensity & 142 & 2 & $1 \%$ & 149 & 2 & $1 \%$ & 12 & 0 & 295 \\
\hline KILWESTC7 & Developed low intensity & 139 & 3 & $2 \%$ & 151 & 2 & $1 \%$ & 12 & 1 & 295 \\
\hline KILARLIN3 & Developed medium intensity & 151 & 2 & $1 \%$ & 150 & 3 & $2 \%$ & 11 & 0 & 306 \\
\hline KILMELRO2 & Developed low intensity & 148 & 2 & $1 \%$ & 150 & 3 & $2 \%$ & 11 & 0 & 303 \\
\hline KILCHICA30 & Developed medium intensity & 146 & 2 & $1 \%$ & 150 & 3 & $2 \%$ & 11 & 0 & 301 \\
\hline KILLYONS1 & Developed medium intensity & 133 & 2 & $1 \%$ & 136 & 3 & $2 \%$ & 11 & 0 & 274 \\
\hline KILLAGRA2 & Developed low intensity & 144 & 2 & $1 \%$ & 128 & 0 & $0 \%$ & 11 & 0 & 274 \\
\hline MAT224 & Developed medium intensity & 128 & 2 & $2 \%$ & 137 & 0 & $0 \%$ & 11 & 0 & 267 \\
\hline KILDESPL6 & Developed medium intensity & 151 & 2 & $1 \%$ & 148 & 5 & $3 \%$ & 10 & 1 & 306 \\
\hline KILEVANS2 & Developed medium intensity & 149 & 4 & $3 \%$ & 149 & 4 & $3 \%$ & 10 & 2 & 306 \\
\hline KILELKGR4 & Developed low intensity & 137 & 3 & $2 \%$ & 149 & 4 & $3 \%$ & 10 & 1 & 293 \\
\hline KILDEERF3 & Developed low intensity & 147 & 0 & $0 \%$ & 143 & 3 & $2 \%$ & 10 & 0 & 293 \\
\hline KILOAKPA1 & Developed high intensity & 130 & 3 & $2 \%$ & 136 & 4 & $3 \%$ & 10 & 1 & 273 \\
\hline MAS935 & Developed low intensity & 129 & 2 & $2 \%$ & 132 & 3 & $2 \%$ & 10 & 0 & 266 \\
\hline KILLYONS3 & Developed medium intensity & 148 & 5 & $3 \%$ & 147 & 6 & $4 \%$ & 9 & 4 & 306 \\
\hline KILPALAT4 & Developed low intensity & 144 & 3 & $2 \%$ & 147 & 6 & $4 \%$ & 9 & 2 & 300 \\
\hline MAT062 & Developed low intensity & 144 & 5 & $3 \%$ & 143 & 6 & $4 \%$ & 9 & 4 & 298 \\
\hline KILCHICA69 & Developed low intensity & 145 & 2 & $1 \%$ & 145 & 2 & $1 \%$ & 9 & 0 & 294 \\
\hline KILPALOS2 & Developed low intensity & 143 & 3 & $2 \%$ & 130 & 6 & $4 \%$ & 9 & 2 & 282 \\
\hline KILNORTH9 & Developed medium intensity & 139 & 4 & $3 \%$ & 133 & 5 & $4 \%$ & 9 & 2 & 281 \\
\hline KILCHICA112 & Developed high intensity & & & & 153 & 0 & $0 \%$ & 9 & 0 & 153 \\
\hline KILCHICA111 & Developed medium intensity & & & & 131 & 0 & $0 \%$ & 9 & 0 & 131 \\
\hline KILORLAN4 & Developed medium intensity & 136 & 7 & $5 \%$ & 140 & 0 & $0 \%$ & 8 & 4 & 283 \\
\hline KILBARRI7 & Developed medium intensity & 117 & 3 & $3 \%$ & 142 & 4 & $3 \%$ & 8 & 1 & 266 \\
\hline KILARLIN6 & Developed low intensity & 135 & 2 & $1 \%$ & 133 & 6 & $4 \%$ & 7 & 1 & 276 \\
\hline KILCHICA105 & Developed high intensity & 130 & 0 & $0 \%$ & & & & 7 & 0 & 130 \\
\hline MAU210 & Developed low intensity & & & & 149 & 3 & $2 \%$ & 6 & 0 & 152 \\
\hline KILOAKLA4 & Developed low intensity & 139 & 12 & $8 \%$ & 144 & 9 & $6 \%$ & 5 & 11 & 304 \\
\hline KILCHICA114 & Developed low intensity & & & & 148 & 4 & $3 \%$ & 5 & 0 & 152 \\
\hline KILWINNE3 & Developed low intensity & & & & 148 & 4 & $3 \%$ & 5 & 0 & 152 \\
\hline KILPALOS4 & Developed medium intensity & & & & 146 & 4 & $3 \%$ & 5 & 0 & 150 \\
\hline KILTINLE1 & Developed medium intensity & 147 & 2 & $1 \%$ & & & & 5 & 0 & 149 \\
\hline KILCHICA115 & Developed medium intensity & & & & 145 & 4 & $3 \%$ & 5 & 0 & 149 \\
\hline KILORLAN5 & Developed high intensity & & & & 144 & 4 & $3 \%$ & 5 & 0 & 148 \\
\hline KILCHICA107 & Developed medium intensity & & & & 129 & 4 & $3 \%$ & 5 & 0 & 133 \\
\hline KILCHICA68 & Developed medium intensity & 142 & 9 & $6 \%$ & & & & 4 & 6 & 151 \\
\hline KILARLIN4 & Developed low intensity & & & & 131 & 6 & $4 \%$ & 3 & 1 & 137 \\
\hline KILROLLI4 & Developed low intensity & & & & 129 & 8 & $6 \%$ & 2 & 2 & 137 \\
\hline
\end{tabular}


TABLe 2: Continued.

\begin{tabular}{|c|c|c|c|c|c|c|c|c|c|c|}
\hline \multirow{2}{*}{$\begin{array}{l}\text { Metro } \\
\text { County } \\
\text { Station } \\
\end{array}$} & \multirow{2}{*}{ Land cover (NLCD 2011) } & \multicolumn{3}{|c|}{2011} & \multicolumn{3}{|c|}{2012} & \multirow{2}{*}{ False pos. } & \multirow{2}{*}{ False neg. } & \multirow{2}{*}{ Obs } \\
\hline & & Norm & Heat & $\%$ & Norm & Heat & $\%$ & & & \\
\hline \multicolumn{11}{|l|}{ DuPage } \\
\hline KILCAROL5 & Developed low intensity & 115 & 0 & $0 \%$ & 151 & 0 & $0 \%$ & 15 & 0 & 266 \\
\hline KILWESTC8 & Developed medium intensity & 149 & 3 & $2 \%$ & 153 & 0 & $0 \%$ & 14 & 1 & 305 \\
\hline KILCLARE2 & Developed low intensity & 147 & 3 & $2 \%$ & 134 & 2 & $1 \%$ & 12 & 1 & 286 \\
\hline CHIAirport & Developed open space & 151 & 2 & $1 \%$ & 150 & 3 & $2 \%$ & 11 & 0 & 306 \\
\hline KILNAPER15 & Developed low intensity & 150 & 3 & $2 \%$ & 149 & 4 & $3 \%$ & 10 & 1 & 306 \\
\hline KILNAPER7 & Developed low intensity & 150 & 3 & $2 \%$ & 149 & 4 & $3 \%$ & 10 & 1 & 306 \\
\hline KILDOWNE3 & Deciduous forest & 150 & 3 & $2 \%$ & 146 & 2 & $1 \%$ & 9 & 1 & 301 \\
\hline KILELMHU5 & Developed low intensity & 136 & 5 & $4 \%$ & 147 & 3 & $2 \%$ & 9 & 3 & 291 \\
\hline KILLISLE3 & Developed open space & 148 & 3 & $2 \%$ & 144 & 6 & $4 \%$ & 9 & 2 & 301 \\
\hline KILLOMBA5 & Developed low intensity & 123 & 0 & $0 \%$ & 149 & 4 & $3 \%$ & 9 & 0 & 276 \\
\hline KILWARRE2 & Developed low intensity & 146 & 2 & $1 \%$ & 142 & 4 & $3 \%$ & 9 & 1 & 294 \\
\hline KILWHEAT5 & Developed medium intensity & 133 & 5 & $4 \%$ & 137 & 0 & $0 \%$ & 9 & 3 & 275 \\
\hline KILWHEAT8 & Developed medium intensity & 121 & 3 & $2 \%$ & 135 & 4 & $3 \%$ & 9 & 1 & 263 \\
\hline MC5020 & Developed medium intensity & 148 & 3 & $2 \%$ & 146 & 3 & $2 \%$ & 9 & 1 & 300 \\
\hline MD1973 & Developed low intensity & 143 & 2 & $1 \%$ & 136 & 5 & $4 \%$ & 9 & 3 & 286 \\
\hline KILNAPER9 & Developed low intensity & 146 & 5 & $3 \%$ & 145 & 8 & $5 \%$ & 8 & 5 & 304 \\
\hline KILWOODR2 & Developed low intensity & 139 & 8 & $5 \%$ & 131 & 6 & $4 \%$ & 8 & 6 & 284 \\
\hline KILWOODR4 & Developed low intensity & 146 & 5 & $3 \%$ & 145 & 8 & $5 \%$ & 8 & 5 & 304 \\
\hline KILCHICA63 & Developed low intensity & 148 & 0 & $0 \%$ & & & & 7 & 0 & 148 \\
\hline KILDARIE3 & Developed low intensity & 135 & 10 & $7 \%$ & 143 & 4 & $3 \%$ & 7 & 6 & 292 \\
\hline KILGLENE1 & Developed low intensity & 130 & 2 & $2 \%$ & 140 & 0 & $0 \%$ & 7 & 0 & 272 \\
\hline KILNAPER19 & Developed medium intensity & 145 & 7 & $5 \%$ & 144 & 8 & $5 \%$ & 7 & 6 & 304 \\
\hline KILWHEAT7 & Developed low intensity & 145 & 3 & $2 \%$ & 139 & 5 & $3 \%$ & 7 & 1 & 292 \\
\hline MD0023 & Developed open space & 128 & 2 & $2 \%$ & 140 & 0 & $0 \%$ & 7 & 0 & 270 \\
\hline KILWESTC5 & Developed low intensity & 150 & 3 & $2 \%$ & & & & 5 & 1 & 153 \\
\hline KILNAPER21 & Developed low intensity & & & & 147 & 6 & $4 \%$ & 4 & 1 & 153 \\
\hline KILGLENE5 & Developed low intensity & & & & 125 & 6 & $5 \%$ & 3 & 3 & 131 \\
\hline KILWHEAT9 & Developed low intensity & & & & 136 & 9 & $6 \%$ & 3 & 3 & 145 \\
\hline \multicolumn{11}{|l|}{ Lake, IL } \\
\hline KILGURNE6 & Developed open space & 146 & 0 & $0 \%$ & 152 & 0 & $0 \%$ & 14 & 0 & 298 \\
\hline KILLAKEB2 & Developed low intensity & 145 & 0 & $0 \%$ & 130 & 0 & $0 \%$ & 14 & 0 & 275 \\
\hline MC2377 & Developed low intensity & 145 & 0 & $0 \%$ & 152 & 0 & $0 \%$ & 14 & 0 & 297 \\
\hline KILDEERF2 & Deciduous forest & 151 & 2 & $1 \%$ & 153 & 0 & $0 \%$ & 12 & 0 & 306 \\
\hline KILLAKEB4 & Developed low intensity & 137 & 2 & $1 \%$ & 142 & 0 & $0 \%$ & 12 & 0 & 281 \\
\hline KILLIBER6 & Developed low intensity & 150 & 2 & $1 \%$ & 153 & 0 & $0 \%$ & 12 & 0 & 305 \\
\hline KILANTIO1 & Developed open space & 151 & 2 & $1 \%$ & 150 & 3 & $2 \%$ & 9 & 0 & 306 \\
\hline KILGURNE1 & Developed open space & 148 & 0 & $0 \%$ & 141 & 3 & $2 \%$ & 9 & 0 & 292 \\
\hline KILGURNE8 & Developed low intensity & 148 & 2 & $1 \%$ & 149 & 3 & $2 \%$ & 9 & 0 & 302 \\
\hline KILMUNDE4 & Open water & 148 & 3 & $2 \%$ & 148 & 3 & $2 \%$ & 8 & 1 & 302 \\
\hline KILGRAYS3 & Developed low intensity & 142 & 5 & $3 \%$ & 148 & 5 & $3 \%$ & 7 & 3 & 300 \\
\hline KILINGLE2 & Developed low intensity & 148 & 5 & $3 \%$ & 148 & 5 & $3 \%$ & 7 & 3 & 306 \\
\hline KILLAKEV6 & Open water & 151 & 2 & $1 \%$ & 145 & 7 & $5 \%$ & 7 & 2 & 305 \\
\hline KILLAKEV7 & Developed medium intensity & 144 & 4 & $3 \%$ & 146 & 4 & $3 \%$ & 7 & 1 & 298 \\
\hline KILWINTH3 & Developed low intensity & 136 & 4 & $3 \%$ & 135 & 4 & $3 \%$ & 7 & 1 & 279 \\
\hline KILLAKEV4 & Developed low intensity & & & & 119 & 3 & $2 \%$ & 6 & 0 & 122 \\
\hline KILLIBER2 & Developed open space & 140 & 0 & $0 \%$ & 116 & 37 & $24 \%$ & 6 & 30 & 293 \\
\hline KILVERNO2 & Developed medium intensity & & & & 147 & 4 & $3 \%$ & 5 & 0 & 151 \\
\hline KILZION4 & Developed open space & & & & 143 & 3 & $2 \%$ & 5 & 0 & 146 \\
\hline KILLAKEZ3 & Developed low intensity & 144 & 9 & $6 \%$ & 145 & 8 & $5 \%$ & 4 & 7 & 306 \\
\hline
\end{tabular}


TABLE 2: Continued.

\begin{tabular}{|c|c|c|c|c|c|c|c|c|c|c|}
\hline \multirow{2}{*}{$\begin{array}{l}\text { Metro } \\
\text { County } \\
\text { Station }\end{array}$} & \multirow{2}{*}{ Land cover (NLCD 2011) } & \multicolumn{3}{|c|}{2011} & \multicolumn{3}{|c|}{2012} & \multirow{2}{*}{ False pos. $^{*}$} & \multirow{2}{*}{ False neg. } & \multirow{2}{*}{ Obs } \\
\hline & & Norm & Heat & $\%$ & Norm & Heat & $\%$ & & & \\
\hline KILTHIRD3 & Deciduous forest & & & & 139 & 9 & $6 \%$ & 4 & 4 & 148 \\
\hline KILBARRI8 & Developed low intensity & & & & 137 & 8 & $6 \%$ & 3 & 2 & 145 \\
\hline KILHIGHL6 & Developed low intensity & & & & 86 & 52 & $38 \%$ & 1 & 46 & 138 \\
\hline \multicolumn{11}{|l|}{ Lake, IN } \\
\hline KINHOBAR5 & Developed medium intensity & 148 & 5 & $3 \%$ & 149 & 4 & $3 \%$ & 10 & 1 & 306 \\
\hline KINLOWEL5 & Cultivated crops & 146 & 7 & $5 \%$ & 146 & 6 & $4 \%$ & 9 & 4 & 305 \\
\hline KINEASTC3 & Developed high intensity & 129 & 2 & $2 \%$ & 126 & 5 & $4 \%$ & 8 & 1 & 262 \\
\hline KINHAMMO3 & Developed low intensity & 135 & 6 & $4 \%$ & 143 & 8 & $5 \%$ & 8 & 5 & 292 \\
\hline KILCRETE1 & Developed low intensity & & & & 124 & 2 & $2 \%$ & 6 & 0 & 126 \\
\hline KINMUNST1 & Developed low intensity & 134 & 15 & $10 \%$ & 143 & 10 & $7 \%$ & 6 & 13 & 302 \\
\hline KINCEDAR4 & Developed low intensity & 139 & 6 & $4 \%$ & 130 & 23 & $15 \%$ & 5 & 17 & 298 \\
\hline KINHAMMO2 & Developed low intensity & 132 & 17 & $11 \%$ & 142 & 10 & $7 \%$ & 5 & 14 & 301 \\
\hline KINLOWEL4 & Cultivated crops & & & & 107 & 8 & $7 \%$ & 1 & 2 & 115 \\
\hline \multicolumn{11}{|l|}{ WILL } \\
\hline KILROMEO4 & Developed open space & 152 & 0 & $0 \%$ & 145 & 0 & $0 \%$ & 18 & 0 & 297 \\
\hline KILWILMI1 & Developed low intensity & 131 & 0 & $0 \%$ & 117 & 0 & $0 \%$ & 18 & 0 & 248 \\
\hline KILMOKEN1 & Developed low intensity & 147 & 0 & $0 \%$ & 148 & 0 & $0 \%$ & 16 & 0 & 295 \\
\hline KILFRANK1 & Developed low intensity & 149 & 3 & $2 \%$ & 147 & 4 & $3 \%$ & 12 & 1 & 303 \\
\hline MWMGI2 & Grassland/herbaceous & 145 & 6 & $4 \%$ & 149 & 4 & $3 \%$ & 12 & 4 & 304 \\
\hline KILBOLIN10 & Developed low intensity & 147 & 2 & $1 \%$ & 133 & 4 & $3 \%$ & 11 & 0 & 286 \\
\hline KILGLENW1 & Cultivated crops & 123 & 9 & $7 \%$ & 121 & 2 & $2 \%$ & 11 & 5 & 255 \\
\hline KILJOLIE4 & Developed low intensity & 149 & 3 & $2 \%$ & 147 & 4 & $3 \%$ & 11 & 1 & 303 \\
\hline KILMINOO3 & Developed low intensity & 148 & 5 & $3 \%$ & 120 & 6 & $5 \%$ & 11 & 4 & 279 \\
\hline KILPLAIN5 & Developed low Intensity & 150 & 3 & $2 \%$ & 147 & 6 & $4 \%$ & 11 & 2 & 306 \\
\hline KILROMEO5 & Developed medium intensity & 135 & 5 & $4 \%$ & 144 & 6 & $4 \%$ & 11 & 4 & 290 \\
\hline KILLOCKP6 & Developed low intensity & 150 & 3 & $2 \%$ & 145 & 7 & $5 \%$ & 10 & 2 & 305 \\
\hline KILPEOTO1 & Developed low intensity & 148 & 5 & $3 \%$ & 148 & 4 & $3 \%$ & 10 & 1 & 305 \\
\hline KILCHANN3 & Developed low intensity & 145 & 5 & $3 \%$ & 129 & 6 & $4 \%$ & 9 & 4 & 285 \\
\hline KILJOLIE12 & Developed medium intensity & 145 & 5 & $3 \%$ & 145 & 8 & $5 \%$ & 9 & 4 & 303 \\
\hline KILPLAIN6 & Developed low intensity & 146 & 6 & $4 \%$ & 147 & 6 & $4 \%$ & 9 & 3 & 305 \\
\hline KILROMEO7 & Developed medium intensity & & & & 151 & 0 & $0 \%$ & 9 & 0 & 151 \\
\hline KILBOLIN8 & Developed open space & 137 & 6 & $4 \%$ & 127 & 8 & $6 \%$ & 7 & 5 & 278 \\
\hline KILELWOO2 & Woody wetlands & 134 & 19 & $12 \%$ & 140 & 13 & $8 \%$ & 6 & 20 & 306 \\
\hline KILJOLIE15 & Developed low intensity & 138 & 15 & $10 \%$ & 143 & 10 & $7 \%$ & 6 & 13 & 306 \\
\hline KILLOCKP1 & Developed medium intensity & 122 & 30 & $20 \%$ & 136 & 15 & $10 \%$ & 6 & 33 & 303 \\
\hline KILMANHA2 & Developed medium intensity & & & & 149 & 4 & $3 \%$ & 5 & 0 & 153 \\
\hline KILNEWLE3 & Developed low intensity & & & & 149 & 4 & $3 \%$ & 5 & 0 & 153 \\
\hline KILNEWLE9 & Developed medium intensity & & & & 148 & 4 & $3 \%$ & 5 & 0 & 152 \\
\hline KILPLAIN15 & Developed low intensity & 115 & 22 & $16 \%$ & 145 & 8 & $5 \%$ & 5 & 17 & 290 \\
\hline KILLOCKP9 & Developed low intensity & & & & 134 & 6 & $4 \%$ & 4 & 1 & 140 \\
\hline KILNEWLE8 & Developed medium intensity & & & & 147 & 6 & $4 \%$ & 4 & 1 & 153 \\
\hline KILPLAIN19 & Developed low intensity & & & & 147 & 6 & $4 \%$ & 4 & 1 & 153 \\
\hline MD9022 & Developed medium intensity & & & & 137 & 6 & $4 \%$ & 4 & 1 & 143 \\
\hline KILBOLIN11 & Developed low intensity & & & & 138 & 15 & $10 \%$ & 3 & 9 & 153 \\
\hline KILBRAID6 & Developed medium intensity & & & & 145 & 8 & $5 \%$ & 3 & 2 & 153 \\
\hline KILPLAIN7 & Developed medium intensity & & & & 142 & 9 & $6 \%$ & 3 & 3 & 151 \\
\hline KILAUROR20 & Developed low intensity & & & & 96 & 45 & $32 \%$ & 1 & 37 & 141 \\
\hline
\end{tabular}

\footnotetext{
${ }^{*}$ Stations within each county are sorted by number of false positives.
} 


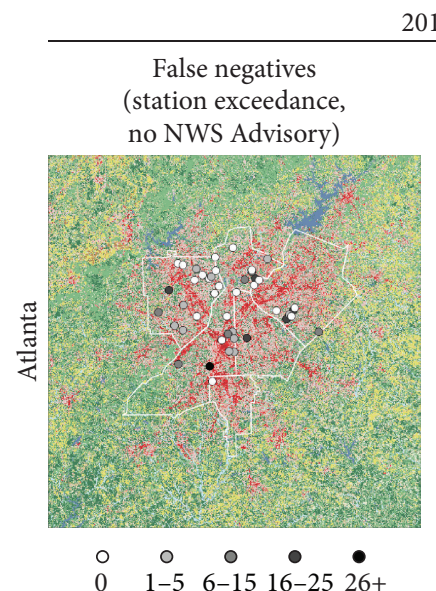

2011

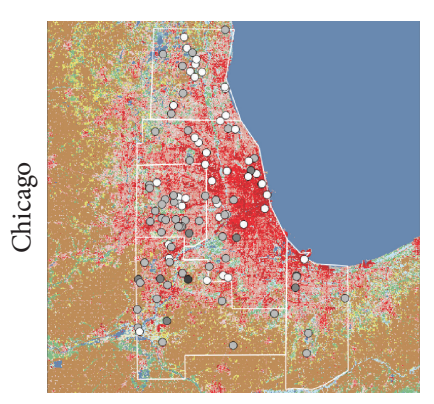

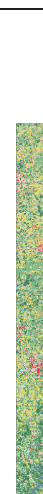

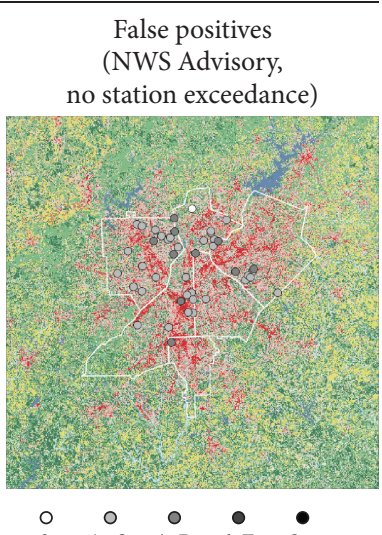

$\begin{array}{lcccc}0 & 1-3 & 4-5 & 6-7 & 8+\end{array}$

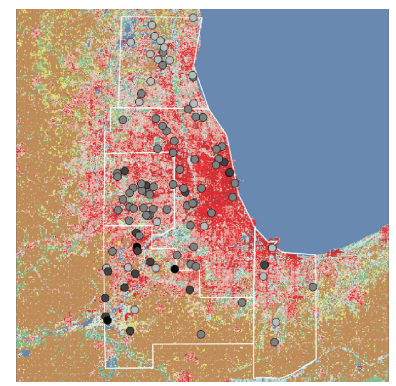

2012

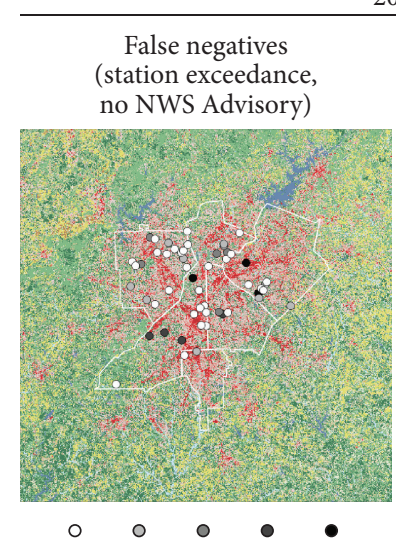

$\begin{array}{ccccc}\circ & \circ & \circ & \bullet & \bullet \\ 0 & 1-5 & 6-15 & 16-25 & 26+\end{array}$

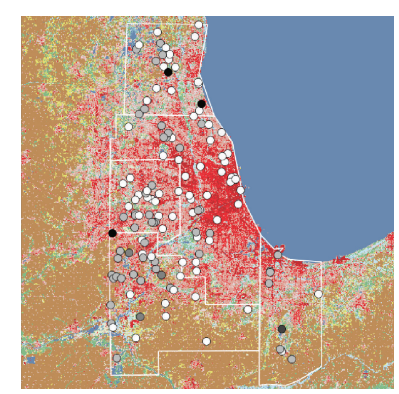

False positives

(NWS Advisory,

no station exceedance)

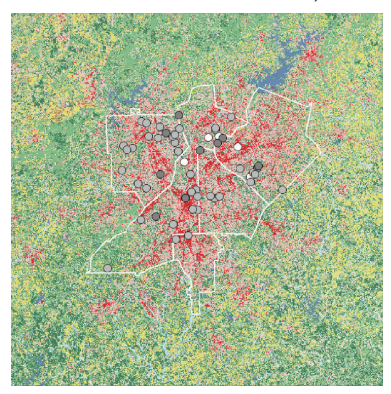

$\begin{array}{ccccc}\circ & \circ & \circ & \bullet & \bullet \\ 0 & 1-3 & 4-5 & 6-7 & 8+\end{array}$

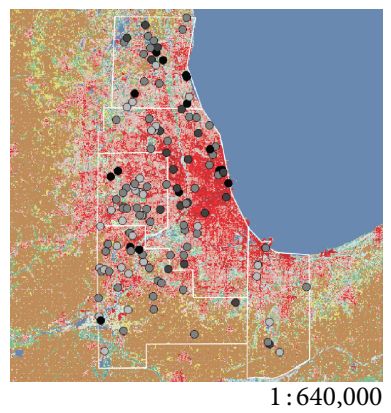

\begin{abstract}
Open water
Perennial ice/snow

Shrub/scrub

Grassland
\end{abstract}

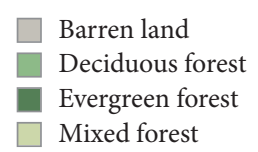

Mixed forest

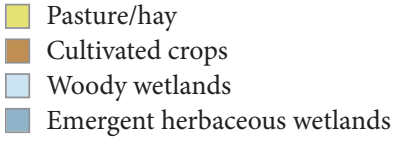
Developed, open space
Developed, low intensity
Developed, medium intensity
Developed, high intensity

FIGURE 3: Stations are presented by the number of false positive and negative instances in 2011 and 2012. The National Land Cover Dataset's (NLCD) 2011 land cover classification scheme is included. A false negative means station conditions exceeded Heat Advisory Criteria with no such Advisory issued from NWS. A false positive is when Heat Advisory conditions at the station were not met despite NWS issuing an advisory.

risk, as is accomplished with a heat index-like factor. In all cases (the six days examined) there was no significant difference in estimated mean temperature between pixels with stations exhibiting Advisory-like conditions and for those with stations measuring heat index values below $105^{\circ} \mathrm{F}$. This perhaps suggests the importance of investigating methods for estimating heat index from satellite imagery sources, for validating the station measurements more thoroughly, and for examining the importance of local drivers of humidity.

We acknowledge that this analysis relies on measurements from weather station data that have not been as closely quality controlled as those from other long-standing weather stations that are part of large national and global networks. We limited our analysis because we believed the 2011-2012 Wunderground weather station data to be more complete than earlier years we investigated. For Atlanta, the fraction of daily observations exhibiting hazardous conditions was similar between the 7-year (4.3\%) and the 2-year $(4.9 \%)$ datasets. For Chicago the fractions were more divergent, $2.1 \%$ for 2006-2012 and 3.3\% for only 2011 and 2012; however, we noticed that the 2006-2010 contained less hazardous heat weather in all datasets (NWS and Wunderground). Though we collected data from a number of years that were not used in the analysis, we expect that our findings are not anomalous in their description of the agreement between NWS and weather station measurements.

\section{Conclusion}

Records from individual weather stations show that the conditions for hazardous heat exposures exist for many locations within counties, even when the forecasted conditions do not call for issued warnings applied to the county. Further analysis of larger, long term datasets is needed to produce a more robust understanding of the interaction of regional weather and local land cover conditions that combine to produce hazardous conditions at specific locations within counties. These factors likely change with time of year and metro area being considered. 


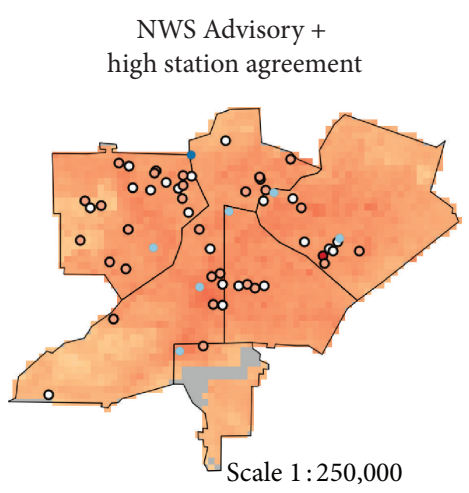

(a) Atlanta July 1, 2012

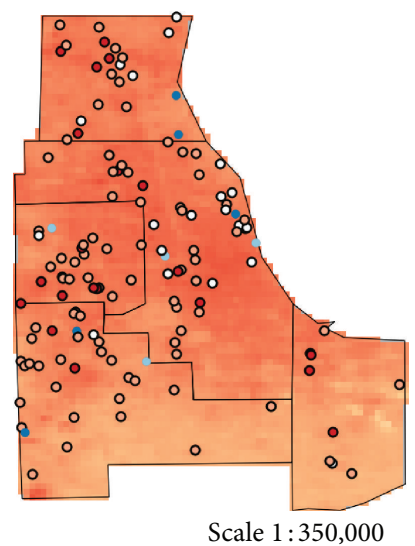

(b) Chicago July 6, 2012

Daily mean air temp (estimated from MODIS)

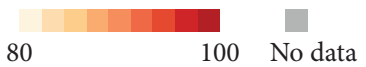

NWS Advisory +

station disagreement

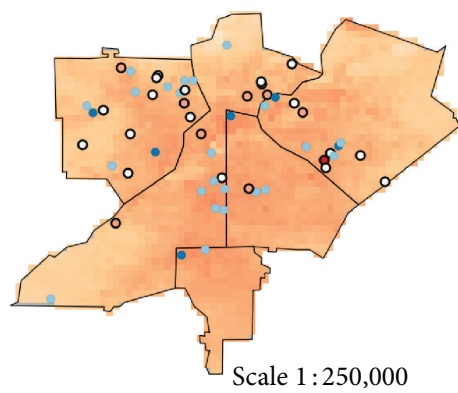

(c) Atlanta June 29, 2012

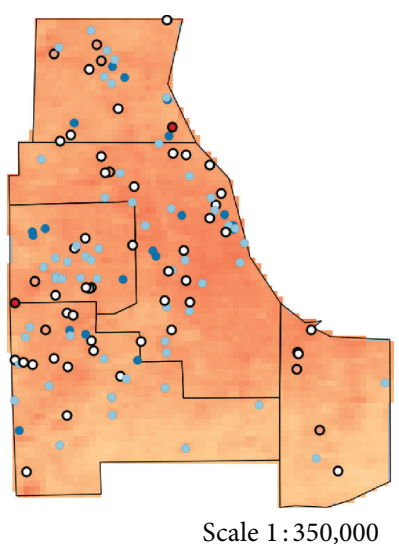

(d) Chicago July 17, 2012
No NWS Advisory + station disagreement

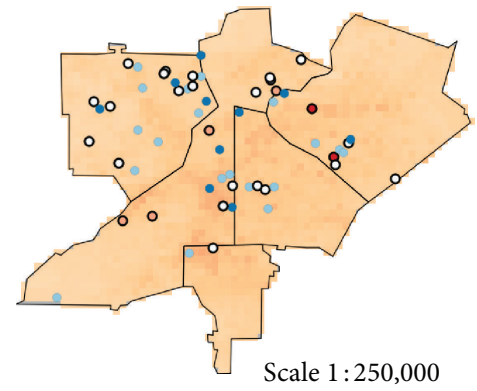

(e) Atlanta July 25, 2012

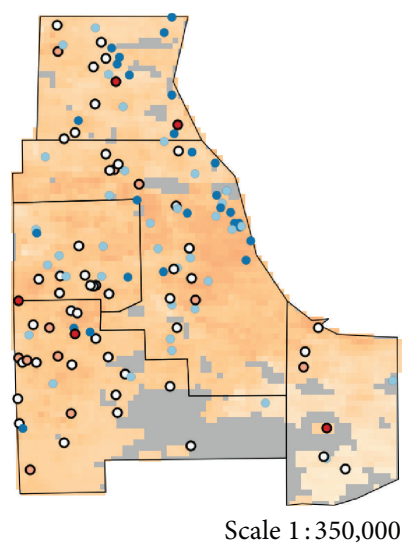

(f) Chicago July 2, 2012

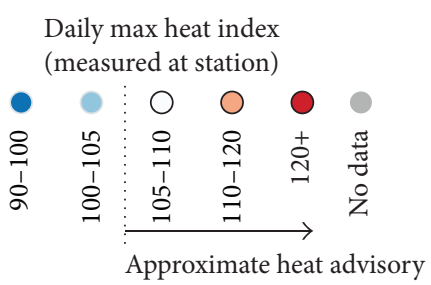

Figure 4: Air temperatures modeled from Land Surface Temperature data from MODIS satellites are shown with station-measured heat index data with varying levels of agreement between NWS Heat Advisory status and station conditions.

\section{Conflict of Interests}

The authors declare that there is no conflict of interests regarding the publication of this paper.

\section{Acknowledgments}

The work of Liu and Xiao was partially supported by NASA Applied Sciences Program (Grants NNX11AI53G and NNX14AG01G, PI: Liu). The authors would also like to thank government climatologists and scientists including Brad Pierce, Ed Hopkins, Barry Gooden, Jim Allsopp, and Rusty Kapela for their conversations as the authors developed this research.

\section{References}

[1] J. Hansen, M. Sato, and R. Ruedy, "Perception of climate change," Proceedings of the National Academy of Sciences of the United States of America, vol. 109, no. 37, pp. E2415-E2423, 2012.

[2] G. A. Meehl and C. Tebaldi, "More intense, more frequent, and longer lasting heat waves in the 21st century," Science, vol. 305, no. 5686, pp. 994-997, 2004.

[3] D. R. Easterling, G. A. Meehl, C. Parmesan, S. A. Changnon, T. R. Karl, and L. O. Mearns, "Climate extremes: observations, modeling, and impacts," Science, vol. 289, no. 5487, pp. 20682074, 2000.

[4] J.-M. Robine, S. L. K. Cheung, S. Le Roy et al., "Death toll exceeded 70,000 in Europe during the summer of 2003," Comptes Rendus: Biologies, vol. 331, no. 2, pp. 171-178, 2008. 
[5] D. Guha-Sapir, F. Vos, R. Below, and S. Ponserre, Annual Disaster Statistical Review 2010, Centre for Research on the Epidemiology of Disasters, 2011.

[6] B. A. Revich, "Heat-wave, air quality and mortality in european russia in summer 2010: preliminary assessment," Human Ecology, no. 7, pp. 3-9, 2011.

[7] D. Habeeb, J. Vargo, and B. Stone, "Rising heat wave trends in large US cities," Natural Hazards, vol. 76, no. 3, pp. 1651-1665, 2015.

[8] R. S. Kovats and S. Hajat, "Heat stress and public health: a critical review," Annual Review of Public Health, vol. 29, pp. 4155, 2008.

[9] J. A. Patz, D. Campbell-Lendrum, T. Holloway, and J. A. Foley, "Impact of regional climate change on human health," Nature, vol. 438, no. 7066, pp. 310-317, 2005.

[10] G. Luber and M. McGeehin, "Climate change and extreme heat events," American Journal of Preventive Medicine, vol. 35, no. 5, pp. 429-435, 2008.

[11] United States Environmental Protection Agency-Office of Atmospheric Programs (6207J), "Excessive heat events guidebook," Tech. Rep. 430-b-06-005, 2006.

[12] M. S. O’Neill, D. K. Jackman, M. Wyman et al., "US local action on heat and health: are we prepared for climate change?" International Journal of Public Health, vol. 55, no. 2, pp. 105-112, 2010.

[13] M. Medina-Ramón and J. Schwartz, "Temperature, temperature extremes, and mortality: a study of acclimatisation and effect modification in 50 US cities," Occupational and Environmental Medicine, vol. 64, no. 12, pp. 827-833, 2007.

[14] R. Basu and J. M. Samet, "Relation between elevated ambient temperature and mortality: a review of the epidemiologic evidence," Epidemiologic Reviews, vol. 24, no. 2, pp. 190-202, 2002.

[15] F. C. Curriero, K. S. Heiner, J. M. Samet, S. L. Zeger, L. Strug, and J. A. Patz, "Temperature and mortality in 11 cities of the eastern United States," American Journal of Epidemiology, vol. 155, no. 1, pp. 80-87, 2002.

[16] K. L. Ebi, T. J. Teisberg, L. S. Kalkstein, L. Robinson, and R. F. Weiher, "Heat watch/warning systems save lives: estimated costs and benefits for Philadelphia 1995-98," Bulletin of the American Meteorological Society, vol. 85, no. 8, pp. 1067-1073, 2004.

[17] M. G. Weisskopf, H. A. Anderson, S. Foldy et al., "Heat wave morbidity and mortality, Milwaukee, Wis, 1999 vs 1995: an improved response?" American Journal of Public Health, vol. 92, no. 5, pp. 830-833, 2002.

[18] M. A. Palecki, S. A. Changnon, and K. E. Kunkel, "The nature and impacts of the July 1999 heat wave in the midwestern United States: learning from the lessons of 1995," Bulletin of the American Meteorological Society, vol. 82, no. 7, pp. 1353-1367, 2001.

[19] C. R. Browning, D. Wallace, S. L. Feinberg, and K. A. Cagney, "Neighborhood social processes, physical conditions, and disaster-related mortality: the case of the 1995 Chicago heat wave," American Sociological Review, vol. 71, no. 4, pp. 661-678, 2006.

[20] M. P. Naughton, A. Henderson, M. C. Mirabelli et al., "Heatrelated mortality during a 1999 heat wave in Chicago," The American Journal of Preventive Medicine, vol. 22, no. 4, pp. 221227, 2002.

[21] O. V. Wilhelmi and M. H. Hayden, "Connecting people and place: a new framework for reducing urban vulnerability to extreme heat," Environmental Research Letters, vol. 5, no. 1, Article ID 014021, 2010.

[22] B. Li, S. Sain, L. O. Mearns et al., "The impact of extreme heat on morbidity in Milwaukee, Wisconsin," Climatic Change, vol. 110, no. 3-4, pp. 959-976, 2012.

[23] R. E. Davis, P. C. Knappenberger, P. J. Michaels, and W. M. Novicoff, "Changing heat-related mortality in the United States," Environmental Health Perspectives, vol. 111, no. 14, pp. 1712-1718, 2003.

[24] F. Salamanca, M. Georgescu, A. Mahalov, M. Moustaoui, and M. Wang, "Anthropogenic heating of the urban environment due to air conditioning," Journal of Geophysical Research: Atmospheres, vol. 119, no. 10, pp. 5949-5965, 2014.

[25] S. C. Sheridan, "A survey of public perception and response to heat warnings across four North American cities: an evaluation of municipal effectiveness," International Journal of Biometeorology, vol. 52, no. 1, pp. 3-15, 2007.

[26] Noaa-national weather service-weather prediction centerheat index probability forecasts, 2014, http://www.hpc.ncep .noaa.gov/heat_index/details_hi.html.

[27] L. S. Kalkstein, P. F. Jamason, J. S. Greene, J. Libby, and L. Robinson, "The Philadelphia hot weather-health watch/warning system: development and application, summer 1995," Bulletin of the American Meteorological Society, vol. 77, no. 7, pp. 1519-1528, 1996.

[28] L. S. Kalkstein and R. E. Davis, "Weather and human mortality: an evaluation of demographic and interregional responses in the United States," Annals of the Association of American Geographers, vol. 79, no. 1, pp. 44-64, 1989.

[29] D. J. Gaffen and R. J. Ross, "Increased summertime heat stress in the US," Nature, vol. 396, no. 6711, pp. 529-530, 1998.

[30] A. J. Kalkstein and S. C. Sheridan, "The social impacts of the heat-health watch/warning system in Phoenix, Arizona: assessing the perceived risk and response of the public," International Journal of Biometeorology, vol. 52, no. 1, pp. 43-55, 2007.

[31] C. Huang, X. Li, and L. Lu, "Retrieving soil temperature profile by assimilating MODIS LST products with ensemble Kalman filter," Remote Sensing of Environment, vol. 112, no. 4, pp. 13201336, 2008.

[32] Z. Wan and Z.-L. Li, "Radiance-based validation of the V5 MODIS land-surface temperature product," International Journal of Remote Sensing, vol. 29, no. 17-18, pp. 5373-5395, 2008.

[33] I. Kloog, A. Chudnovsky, P. Koutrakis, and J. Schwartz, “Temporal and spatial assessments of minimum air temperature using satellite surface temperature measurements in Massachusetts, USA," Science of the Total Environment, vol. 432, pp. 85-92, 2012.

[34] B. Stone, J. Vargo, and D. Habeeb, "Managing climate change in cities: will climate action plans work?" Landscape and Urban Planning, vol. 107, no. 3, pp. 263-271, 2012.

[35] S. I. Corporation, "Chicago Uses Satellite Images to Determine City's True Hot Spots," Satellite Image News, 2006, http://news .satimagingcorp.com/2006/10/chicago_uses_satellite_images_to _determine_citys_true_hot_spots.html.

[36] J. A. Voogt and T. R. Oke, “Thermal remote sensing of urban climates," Remote Sensing of Environment, vol. 86, no. 3, pp. 370384, 2003.

[37] J. Patz, D. Campbell-Lendrum, H. Gibbs, and R. Woodruff, "Health impact assessment of global climate change: expanding on comparative risk assessment approaches for policy making," Annual Review of Public Health, vol. 29, pp. 27-39, 2008. 
[38] J. H. Sorensen, "Hazard warning systems: review of 20 years of progress," Natural Hazards Review, vol. 1, no. 2, pp. 119-125, 2000.

[39] National Rearch Council, Public Response to Alerts and Warnings on Mobile Devices: Summary of a Workshop on Current Knowledge and Research Gaps, National Rearch Council, 2011.

[40] M. A. Casteel and J. R. Downing, "How individuals process NWS weather warning messages on their cell phones," Weather, Climate, and Society, vol. 5, no. 3, pp. 254-265, 2013.

[41] S. Savelli and S. Joslyn, "The advantages of predictive interval forecasts for non-expert users and the impact of visualizations," Applied Cognitive Psychology, vol. 27, no. 4, pp. 527-541, 2013. 

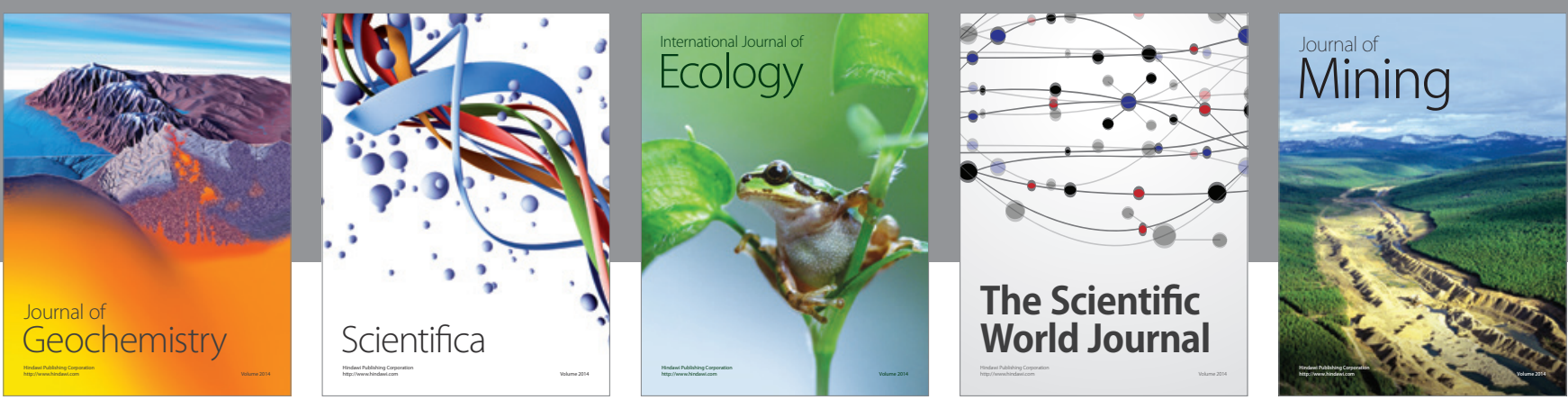

The Scientific World Journal
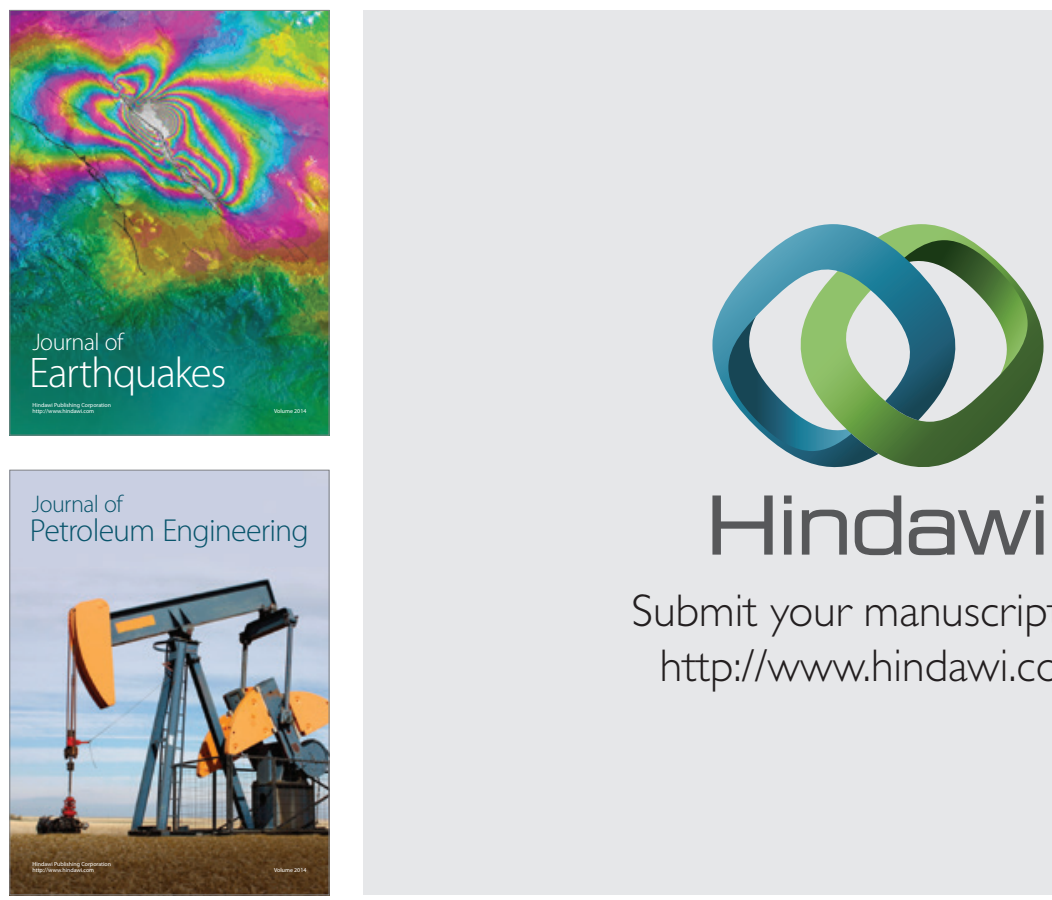

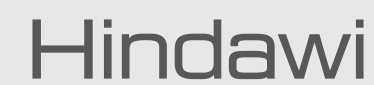

Submit your manuscripts at

http://www.hindawi.com
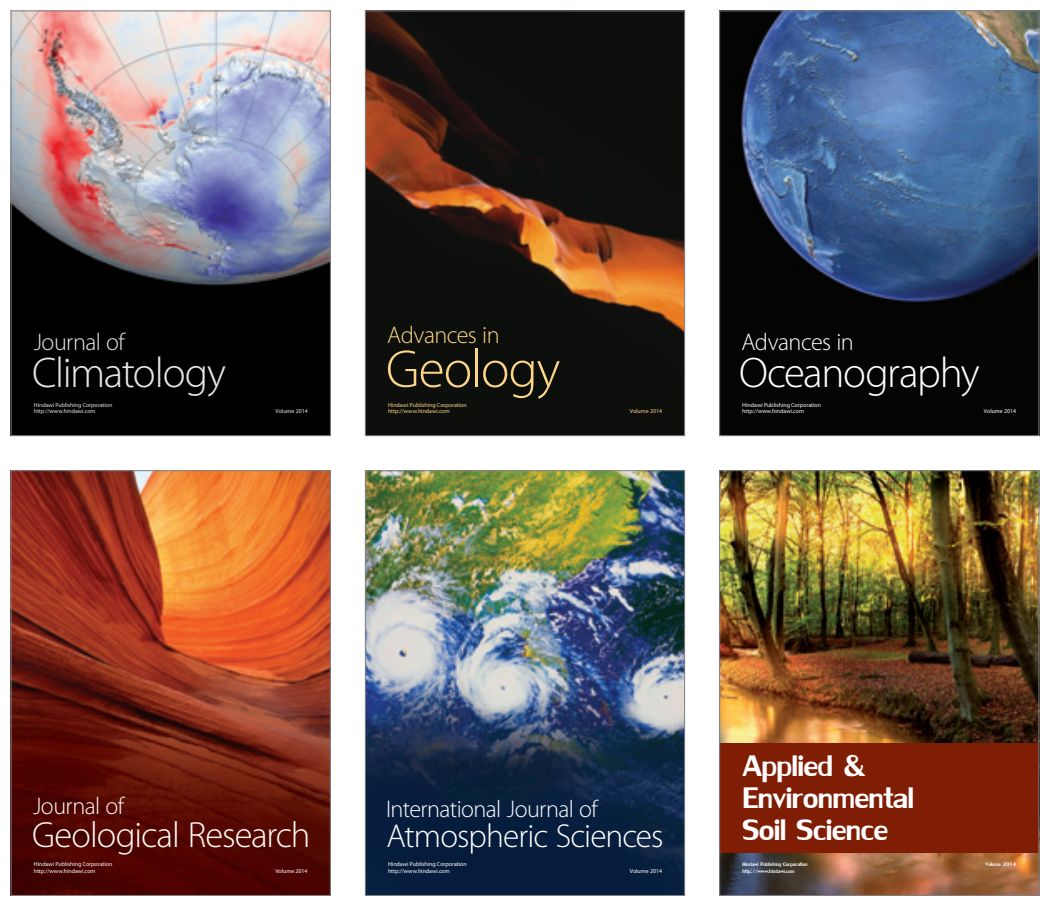
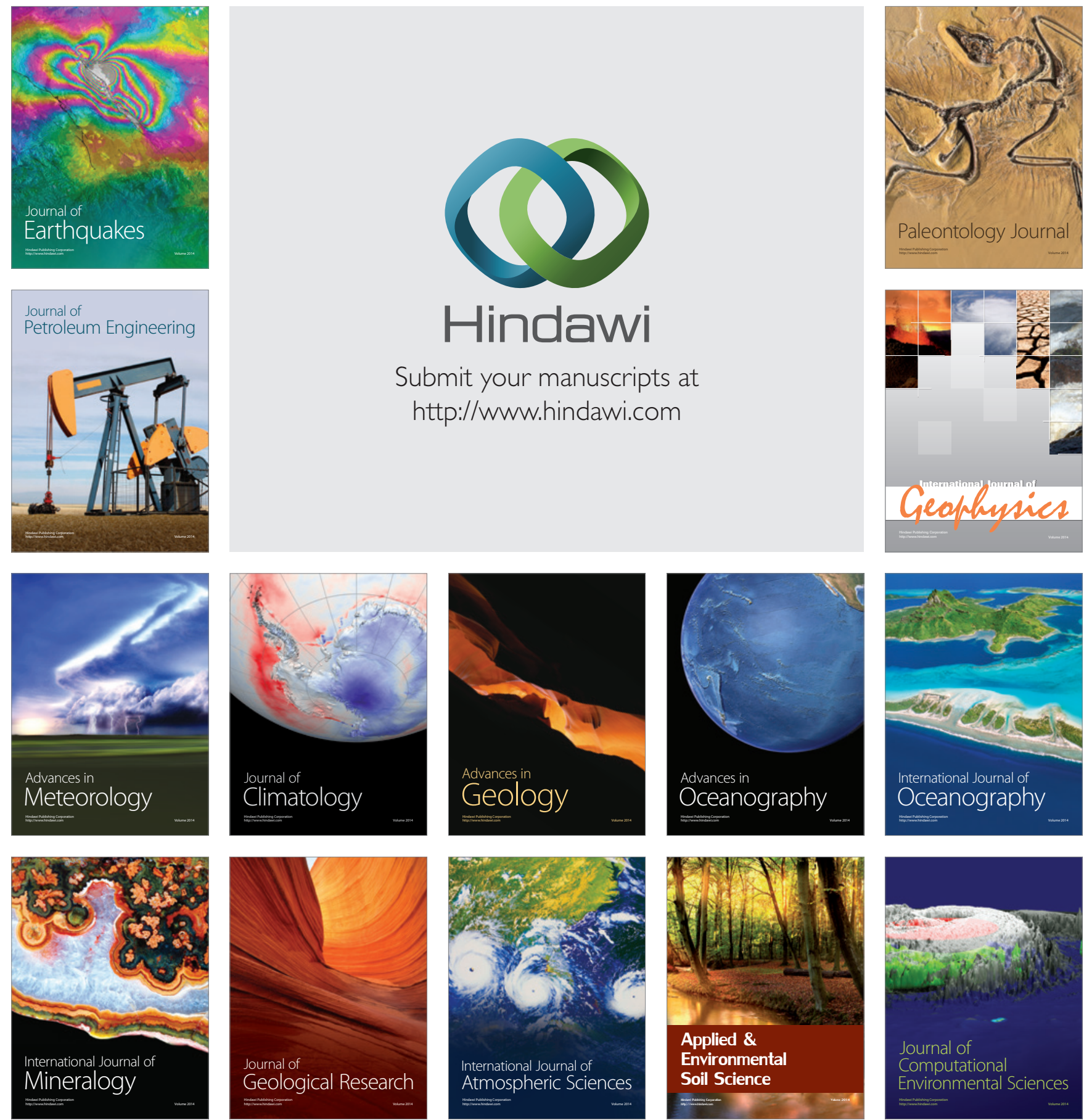